\title{
Characterization of respiratory infection viruses in hospitalized children from Naples province in Southern Italy
}

\author{
CHIARA BOTTI $^{1}$, ALBERTO MICILLO ${ }^{1}$, GIUSEPPE RICCI ${ }^{1}$, ADOLFO RUSSO ${ }^{1}$, ALBERTO DENISCO $^{1}$, \\ MONICA CANTILE $^{2}$, GIOSUÈ SCOGNAMIGLIO ${ }^{2}$, ANTONIO DE ROSA ${ }^{1}$ and GERARDO BOTTI ${ }^{2}$ \\ ${ }^{1}$ Laboratory of Clinical Pathology, Santobono-Pausilipon Hospital, I-80129 Naples; \\ ${ }^{2}$ Pathology Unit, National Cancer Institute 'Pascale Foundation', I-80131 Naples, Italy
}

Received July 6, 2017; Accepted October 2, 2017

DOI: $10.3892 / \mathrm{etm} .2018 .6061$

\begin{abstract}
Most acute respiratory infections (ARIs) in children are due to viral etiology, and represent an important cause of mortality and morbidity in children $<5$ years old in developing countries. The pathogens that cause ARIs vary geographically and by season, and viruses serve a major role. In the present study, the distribution of the seven respiratory viruses that are more prevalent in Southern European countries were retrospectively analyzed in a Southern Italy Hospital, that centralizes pediatric diseases from the Naples province. Viruses were categorized by a FilmArray Respiratory Panel, and demonstrated no substantial differences in sex, age and seasonal viruses distribution. However, all the investigated viruses had a higher detection rate in the surrounding municipalities than in the metropolitan area of Naples. In recent years, the association between air pollution and respiratory infections has become an increasing public health concern. The data in this study support this association in the surrounding areas of Naples extensively contaminated by environmental toxic agents. In these areas, characterization of the epidemiology of ARIs is required to implement a prevention and control program.
\end{abstract}

\section{Introduction}

Acute respiratory infections (ARIs) represent a health issue of great importance, leading cause of mortality in children worldwide, particularly in developing countries (1). These represent

Correspondence to: Dr Monica Cantile, Pathology Unit, National Cancer Institute 'Pascale Foundation', via Mariano Semmola 1, I-80131 Naples, Italy

E-mail:m.cantile@istitutotumori.na.it

Dr Chiara Botti, Laboratory of Clinical Pathology, Santobono-Pausilipon Hospital, via Mario Fiore 6, I-80129 Naples, Italy

E-mail: c.botti@santobonopausilipon.it

Key words: respiratory infection viruses, geographical distribution, pollutants about $50 \%$ of all diseases in children aged $<5$ years (2). The major viral agents of ARI include influenza A, B, and $C$ viruses (FLU), respiratory syncytial virus (RSV), parainfluenza virus (PIV), adenovirus (ADV), human metapneu-movirus (hMPV), human coronavirus (HCoV), and Rhinovirus (HRV).

The etiology of respiratory diseases is multifactorial and includes, among others, interactions between genetic predisposition and environmental factors (3). Numerous studies have confirmed that short- and long-term exposures to ambient air pollutants can be associated with a wide range of pathologies, in particular respiratory diseases and cancer. Although air pollution has not been shown as the sole cause of respiratory infections, it has been reported that several air pollutants were correlated with increased morbidity of respiratory infections (4). In urban areas, irrespective of seasonal frequencies, this correlation increases due to the high incidence of polluting factors. Several epidemiological studies have documented a positive association between exposure to particulate air pollution and respiratory symptoms especially among children (5-7).

It is profusely reported that during the past three decades, large areas of Naples county in the Southern Italy Campania region have been extensively contaminated by environmental toxic agents, in particular for the presence of many landfills of industrial wastes. This region was already defined as one of the geographical areas most at risk of neoplastic and respiratory diseases for environmental factors in the report of WHO (World Health Organization) in 1997 (8).

Although, the epidemiological studies for the association between air pollution and the incidence of respiratory infection in this geographical area are relatively few, virus types identification and their molecular characterization is fundamental not only for surveillance, for diagnostic and therapeutic purposes, but also for highlight the relationships between respiratory diseases in children and concentrations of environment pollutions (9).

In the present study we characterized the viral spectrum and pattern of ARIs in children from children's hospital 'Santobono Pausillipon' which centralizes pediatric diseases of the entire Naples province. The aim of this study was to determine the association between respiratory viruses types, patients features (sex, age, season of disease occurrence) and, in particular, geographical origin. 


\section{Materials and methods}

Patients selection. We retrospectively reviewed the electronic medical records of 356 patients between 11 days and 14 years, with suspected respiratory infection, evaluated at the Santobono Hospital of Naples, between 1 January 2016 and 31 January 2017, with FilmArray ${ }^{\circledR}$ Respiratory Panel (FARP) testing on NasoPharyngeal Swab (NPS).

From patient electronic medical records the following information was obtained: Demographics (age and sex), month of hospitalization, and geographical origin.

We have divided the patients into three age groups (Early childhood, 0-2 years; preschool age, 2-5 years; third childhood: 5-11 years), in the season of hospitalization (winter: December, January, February; spring: March, April, May; summer: June, July, August; autumn: September, October, November) and geographical origin (metropolitan area of Naples and extra-urban areas).

FilmArray testing. NPSs were collected according to a standard procedure, kept in viral transport medium, and stored at $-20^{\circ} \mathrm{C}$ prior to analysis.

FARP (FilmArray ${ }^{\circledR}$ Respiratory Panel BioFire Diagnostics LLC 390; Wakara Way Salt Lake City, UT, USA) is a test based on multiplex PCR. The FilmArray RP cartridge is designed for the simultaneous detection and identification of following viruses and bacteria of the upper respiratory tract: Influenza A virus (H1N1, H1N1 2009, and H3N2), influenza B virus, RSV, PIVs 1-4, ADV, HRV/enterovirus (the assay does not distinguish between these two pathogens), $\mathrm{HMPV}, \mathrm{HCoV}$ (229E, HKU1, OC43, and NL63), Mycoplasma pneumoniae, Chlamydophila pneumoniae, and Bordetella pertussis. The FilmArray instrument and pouch system have been described in detail elsewhere (10). The research use only version of the FilmArray RP system reported a cycle threshold for each positive PCR assay (11).

Statistical analysis. Statistical analysis was performed using SPSS 13.0 (SPSS Inc., Chicago, IL, USA). Viral prevalence were compared using the Chi-square test for categorical variables, and the cartogram was drawn using Excel software (Microsoft Corporation, Redmond, WA, USA). P<0.05 was considered to indicate a statistically significant difference.

\section{Results}

Demographic characteristics. A total of 356 nasopharyngeal swabs were collected and analyzed. In detail, 163 patients were female $(45.78 \%)$ and 193 were male $(54.21 \%)$. Most of the patients (319) were $<5$ years old while 36 patients were $>5$ years old. Patients are heterogeneously distributed in different seasons, while regarding geographical origin, 123 (37.9\%) patients are of Naples metropolitan area, 201 (62.03\%) originated from neighboring municipalities, and for 32 patients this information is lacking.

In our study we considered only viral infections, but we detected also other etiologic agents (Bordetella pertussis, Chlamydophila pneumoniae, Mycoplasma pneumoniae), highlighted the presence of these infections in 24 patients $(6.7 \%)$.

\section{Respiratory infection viruses distribution}

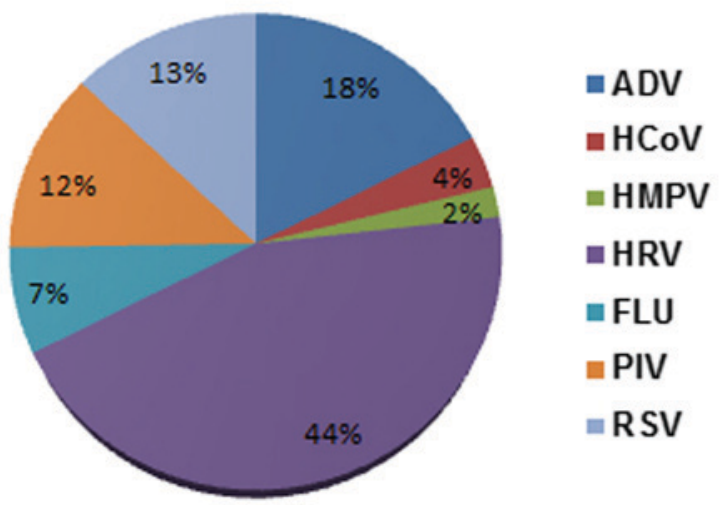

Figure 1. Respiratory infection viruses distribution in hospitalized children.

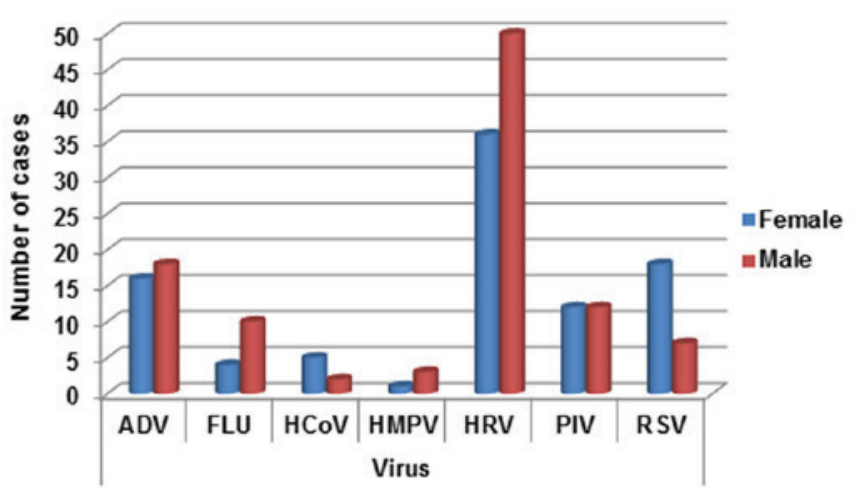

Figure 2. Respiratory infection viruses distribution in male and female patients. ADV, adenovirus; FLU, influenza A, B, and $\mathrm{C}$ viruses; $\mathrm{HCoV}$, human coronavirus; HMPV, human metapneu-movirus; HRV, rhinovirus; PIV, parainfluenza virus; RSV, respiratory syncytial virus.

Respiratory infection viruses distribution. The total rate of detection of all seven viruses was $78 \%(278 / 356)$ of patients. In detail, HRV viruses were detected in $44 \%$ of patients, followed by ADV viruses (18\%), RSV viruses (13\%), and PIV (12\%). A lower incidence has been instead highlighted for FLU (7\%), $\mathrm{HCoV}(4 \%)$ and HMPV (2\%) (Fig. 1).

In a significant proportion of individuals co-infections were also highlighted. In detail, double co-infections were detected in 69/256 (26.9\%) patients, triple in 17/256 (6.6\%) and quadruple infections only in 1 patient (Table I). The more frequent association was detected between HRV and PIV viruses 19/87 (21\%), followed by HRV and ADV viruses 15/87 (17.24\%), and HRV and RSV viruses 9/87 (10.3\%) (Table I).

Sex and age distribution. Viruses appear heterogeneously distributed between sex, with the exception of PIV. In detail, ADV was slightly higher in males $(18 / 34,52.9 \%)$, while FLU (10/14, 71.4\%), HMPV (3/4, 75\%) and HRV (50/86, 58.13\%) were strongly higher in males children (see detection rate Fig. 2). On the contrary $\mathrm{HCoV}(5 / 7,71.4 \%)$ and $\mathrm{RSV}(18 / 25$, $72 \%$ ) are better represented in female patients (see Fig. 2).

Regarding age distribution a decline in the incidence of viral infections with age was observed for respiratory viruses, except for FLU (Fig. 3). In fact the detection rate for FLU viruses was lowest in 2-5 years patients. The detection rate for 
Table I. Co-infections with seven respiratory viruses.

\begin{tabular}{|c|c|}
\hline Co-infections & $\mathrm{N}$ \\
\hline HRV + PIV & 19 \\
\hline $\mathrm{HRV}+\mathrm{ADV}$ & 15 \\
\hline $\mathrm{HRV}+\mathrm{RSV}$ & 9 \\
\hline HRV + ADV + PIV & 4 \\
\hline $\mathrm{ADV}+\mathrm{PIV}$ & 4 \\
\hline HRV + HMPV & 4 \\
\hline HRV-ADV + HCoV & 3 \\
\hline ADV + FLU & 3 \\
\hline $\mathrm{RSV}+\mathrm{HCoV}$ & 3 \\
\hline $\mathrm{ADV}+\mathrm{HCoV}$ & 2 \\
\hline FLU + RSV & 2 \\
\hline $\mathrm{HRV}+\mathrm{HCoV}$ & 2 \\
\hline $\mathrm{HCoV}+\mathrm{PIV}$ & 2 \\
\hline RSV + ADV + HMPV & 2 \\
\hline HRV + RSV + ADV & 2 \\
\hline RSV + HMPV & 2 \\
\hline HRV + RSV + PIV & 2 \\
\hline FLU + PIV & 1 \\
\hline HRV + FLU & 1 \\
\hline $\mathrm{HRV}+\mathrm{HCoV}$ + PIV & 1 \\
\hline $\mathrm{RSV}+\mathrm{ADV}+\mathrm{HRV}$ + PIV & 1 \\
\hline $\mathrm{RSV}+\mathrm{ADV}+\mathrm{HCoV}$ & 1 \\
\hline $\mathrm{HRV}+\mathrm{RSV}+\mathrm{HCoV}$ & 1 \\
\hline HRV + RSV + HMPV & 1 \\
\hline
\end{tabular}

FLU, influenza A, B, and C viruses; RSV, respiratory syncytial virus; PIV, parainfluenza virus; ADV, adenovirus; hMPV, human metapneu-movirus; $\mathrm{HCoV}$, human coronavirus; HRV, rhinovirus.

ADV gradually decrease from $0-2$ years patients to $>5$ years patients. The same trend was highlighted for $\mathrm{HCoV}, \mathrm{PIV}, \mathrm{HRV}$ and RSV (with a consistently increasing of detection rate in 0-2 year-old patients). HMPV was detected prevalently in 0-2 year-old children (Fig. 3).

Seasonal distribution. The total detection rate for all respiratory viruses in spring, summer, autumn and winter was calculated. The rates of detection was more heterogeneous during the different seasons.

In detail, ADV infection was prevalent in summer (20/34, 58.8\%) and spring (10/34, 29.4\%) seasons, FLU was prevalent in spring $(7 / 14,50 \%)$ and winter $(4 / 14,28.5 \%)$, HMPV in winter $(2 / 4,50 \%), \mathrm{HCoV}$ in autumn/winter $(3 / 7$, $42.8 \%)$, HRV in autumn $(34 / 86,39.5 \%)$ and summer $(30 / 86$, $34.8 \%)$, PIV in summer $(13 / 24,34.8 \%)$ and RSV in winter (24/25, 96\%) (Fig. 4).

Geographical distribution. The pediatric patients were divided into two main groups according to origin from the metropolitan of Naples and neighboring municipalities. The detection rates for the two areas appear different with a prevalent distribution in extra-urban areas. This appears more evident especially for ADV, HRV and RSV viral infections (Fig. 5).

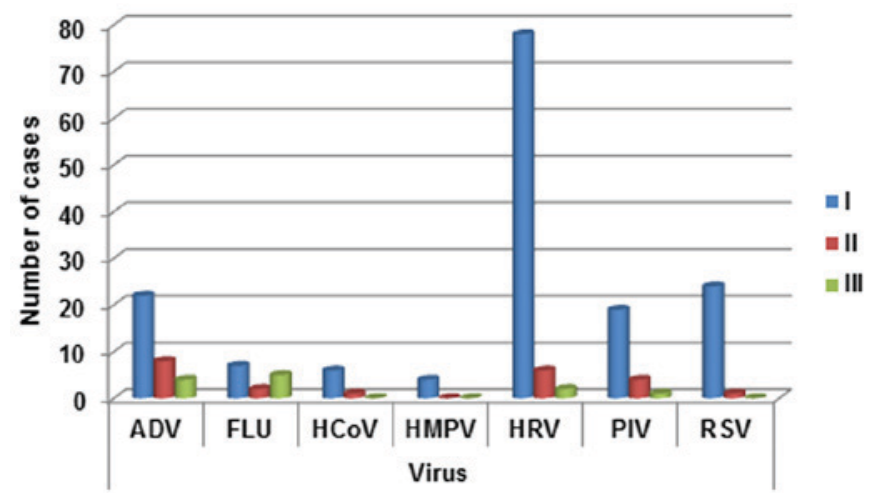

Figure 3. Respiratory infection viruses distribution in the three age groups (0-2 years, $2-5$ years; $>5)$. ADV, adenovirus; FLU, influenza A, B, and C viruses; $\mathrm{HCoV}$, human coronavirus; HMPV, human metapneu-movirus; HRV, rhinovirus; PIV, parainfluenza virus; RSV, respiratory syncytial virus.

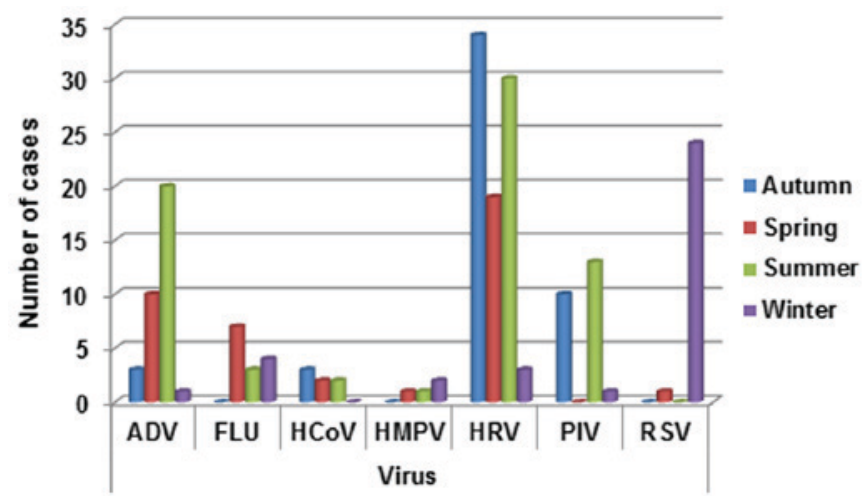

Figure 4. Respiratory infection viruses distribution by season (winter: December, January, February; spring: March, April, May; summer: June, July, August; autumn: September, October, November). ADV, adenovirus; FLU, influenza A, B, and C viruses; $\mathrm{HCoV}$, human coronavirus; HMPV, human metapneu-movirus; HRV, rhinovirus; PIV, parainfluenza virus; RSV, respiratory syncytial virus.

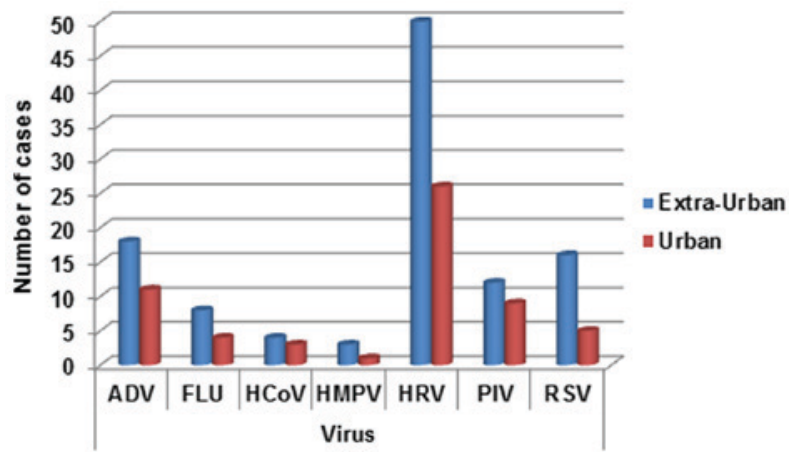

Figure 5. Respiratory infection viruses distribution for territorial origin (urban, Naples metropolitan area; extra-urban, neighboring municipalities). ADV, adenovirus; FLU, influenza A, B, and $\mathrm{C}$ viruses; $\mathrm{HCoV}$, human coronavirus; HMPV, human metapneu-movirus; HRV, rhinovirus; PIV, parainfluenza virus; RSV, respiratory syncytial virus.

\section{Discussion}

WHO reported that ARI can represent among the leading causes of mortality in children under 5 years of age. 
Many studies in the literature have described in detail the viruses mainly associated with ARI and also their distribution, but showing much conflicting data on populations from different countries (1). These variations may be due to socio-economic factors, geographical and climatic differences and efficiency of local health care systems.

In recent years, advances in PCR techniques have aided in the rapid and accurate detection of common respiratory pathogens from patient specimens. Multiplex PCR can identify and differentiate a large panel of viral and bacterial targets simultaneously and are more rapid and more sensitive methods than cultures or antigen detection $(12,13)$.

In the present report we analyzed the distribution of seven respiratory viruses in a case series of 356 hospitalized patients in metropolitan area of Naples and in the neighboring municipalities. The incidence of all analyzed virus is prevalent in early childhood. The distribution of viruses, considered individually, appears to be very heterogeneous, with the largest percentage of HRV in line with other studies on different populations $(14,15)$. HRV (including Rhinovirus and Enterovirus) are RNA viruses related to Picornavirus family (16). HRV is associated with the common cold, but can also be implicated in exacerbating asthma attacks and severe complications (15). The Enteroviruses are categorized into four species, which include a total of 89 serotypes associated with different clinical manifestations $(16,17)$.

In our case series HRV appears more expressed in the male population and its seasonality is mainly associated with summer and autumn, in line with the data present in the literature $(16,18)$.

RSV and ADV are, after HRV, the most common virus in our case series, with RSV prevalent among the female children and ADV among the male population.

RSV is a member of the Paramyxoviridae RNA viruses family related to human metapneumovirus and PIVs. RSV is the most common cause of severe respiratory illness in infants with acute bronchiolitis as a leading cause of hospitalization (19).

In our case series the winter seasonality of RSV viruses corresponds to the other reported data (19).

ADVs are DNA viruses uncoated consists of seven species (A-G) and classified by hemagglutination with about 55 serotypes. The species of ADV B, C and E cause acute respiratory disease with the main risk factor the long stay indoors (18) while the ADV (species A, D, F and G) can cause cystitis, gastroenteritis and conjunctivitis (20).

In our study the seasonal distribution of ADV is prevalent in summer in line with the literature (21).

While there are no substantial differences in PIV distribution, FLU seems prevalent in the male population and their seasonality is consistent with data reported in the literature (22). Finally, $\mathrm{HCoV}$ and hMPV viruses are less frequent in our population, with the first more present in male pediatric population and hMPV in female children.

Coronavirus $\mathrm{HCoV}$ are characterized 4 serological variants (229E, HKU1, NL63 and OC43), and are most commonly associated with infections of the upper respiratory tract (23).

hMPV belong to the Paramyxoviridae family and the infection in newborns and young children is commonly associated with bronchiolitis (24).
It is also widely documented the occurrence of co-infections in some cases. In our case series the more frequent co-infection are between HRV and PIV viruses and HRV and ADV viruses. These data, in some cases, contrast with other reports (25). However, this might be closely related to the geographical location, climate and different social and socio-cultural conditions.

Co-infections were more common in pediatric patients than in adults as documented by other studies (26-28).

However, multiple viral infections can be linked to hospital stay, abuse of antibiotic and social conditions, but there are not proves that co-infections can worsen the disease course. Our hospital centralizes the majority of patients coming from the metropolitan area of Naples but also from neighboring municipalities. Our data are interesting for the geographic distribution of patients. In fact all the investigated viruses have a detection rate higher in surrounding municipalities than in the metropolitan area of Naples. This is in contrast with most of the data present in the literature, where the prevalence is just in urban areas due to the high presence of pollutants (29-31).

However, during the past three decades, surrounding areas of Naples have been extensively contaminated by environmental toxic agents, in particular for the presence of many landfills of industrial wastes. The most contaminated areas were defined as 'Land of Fire' (32).

The relationship between air pollution and respiratory infections has become an increased public health concern in recent years (33-35). In fact, the etiology of respiratory diseases is multifactorial and includes, among others, interactions between genetic predisposition and environmental factors as climate change, chemical air pollution and airborne pollens. The short-term respiratory effects of air pollution include decreases in pulmonary function (36), increases in inflammatory biomarkers and respiratory symptoms (37), infections (38), and respiratory mortality (39).

The environmental risk factors may have an impact on children's respiratory health, above all in urban areas, especially because children inhale more pollutants per kilogram of body weight than adults (40).

In conclusion, the risk factors between populations can be extremely different, suggesting the need to adequately characterize epidemiology of ARIs to implement prevention and control program.

\section{References}

1. Simoes EAF, Cherian T, Chow J, Shahid-Salles SA, Laxminarayan R and John TJ: Acute respiratory infections in children. In: Source Disease Control Priorities in Developing Countries. Jamison DT, Breman JG, Measham AR, Alleyne G, Claeson M, Evans DB, Jha P, Mills A and Musgrove P (eds). second edition. Washington (DC): World Bank, 2006.

2. Shi T, McLean K, Campbell H and Nair H: Aetiological role of common respiratory viruses in acute lower respiratory infections in children under five years: A systematic review and meta-analysis. J Glob Health 5: 010408, 2015.

3. Decramer M, Janssens W and Miravitlles M: Chronic obstructive pulmonary disease. Lancet 379: 1341-1351, 2012.

4. Kurt OK, Zhang J and Pinkerton KE: Pulmonary health effects of air pollution. Curr Opin Pulm Med 22: 138-143, 2016.

5. Pierse N, Rushton L, Harris RS, Kuehni CE, Silverman M and Grigg J: Locally generated particulate pollution and respiratory symptoms in young children. Thorax 61: 216-220, 2006. 
6. Qian Z, Chapman RS, Hu W, Wei F, Korn LR and Zhang JJ: Using air pollution based community clusters to explore air pollution health effects in children. Environ Int 30: 611-620, 2004.

7. Ramani VK, Pattankar J and Puttahonnappa SK: Acute respiratory infections among under-five age group children at urban slums of Gulbarga City: A longitudinal study. J Clin Diagn Res 10: LC08-LC13, 2016.

8. The World Health Report 1997-conquering suffering, enriching humanity. World Health Forum 18: 248-260, 1997.

9. Moreno-Valencia Y, Hernandez-Hernandez VA Romero-Espinoza JA, Coronel-Tellez RH, Castillejos-Lopez M, Hernandez A, Perez-Padilla R, Alejandre-Garcia A, La Rose-Zamboni D, E. Ormsby C and Vazquez-Perez JA: Detection and characterization of respiratory viruses causing acute respiratory illness and asthma exacerbation in children during three different seasons (2011-2014) in Mexico City. Influen Other Resp Virus 9: 287-292, 2015.

10. Poritz MA, Blaschke AJ, Byington CL, Meyers L, Nilsson K, Jones DE, Thatcher SA, Robbins T, Lingenfelter B, Amiott E, et al: FilmArray, an automated nested multiplex PCR system for multi-pathogen detection: Development and application to respiratory tract infection. PLoS One 6: e26047, 2011.

11. Hammond SP, Gagne LS, Stock SR, Marty FM, Gelman RS, Marasco WA, Poritz MA and Baden LR: Respiratory virus detection in immunocompromised patients with FilmArray respiratory panel compared to conventional methods. J Clin Microbiol 50: 3216-3221, 2012.

12. Elnifro EM, Ashshi AM, Cooper RJ and Klapper PE: Multiplex PCR: Optimization and application in diagnostic virology. Clin Microbiol Rev 13: 559-570, 2000.

13. Shibib DR, Matushek SM, Beavis KG, Gawel SH and Charnot-Katsikas A: BioFire filmarray respiratory panel for detection of enterovirus D68. J Clin Microbiol 54: 457-459, 2016.

14. Miller EK, Lu X, Erdman DD, Poehling KA, Zhu Y, Griffin MR, Hartert TV, Anderson LJ, Weinberg GA, Hall CB, et al: Rhinovirus-associated hospitalizations in young children. J Infect Dis 195: 773-781, 2007.

15. Asner SA, Petrich A, Hamid JS, Mertz D, Richardson SE and Smieja M: Clinical severity of rhinovirus/enterovirus compared to other respiratory viruses in children. Influenza Other Respir Viruses 8: 436-442, 2014.

16. Anzueto A and Niederman MS: Diagnosis and treatment of rhinovirus respiratory infections. Chest 123: 1664-1672, 2003.

17. Jacques J, Moret H, Minette D, Lévêque N, Jovenin N, Deslée G, Lebargy F, Motte J and Andréoletti L: Epidemiological, molecular, and clinical features of enterovirus respiratory infections in French children between 1999 and 2005. J Clin Microbiol 46: 206-213, 2008

18. Romero JR, Enteroviruses and Parechoviruses: In: Manual of Clinical Microbiology. Murray PR, Baron EJ, Jorgensen MA, Pfaller MA, Landry ML (eds). ASM press, Washington D.C., pp 1392-1404, 2007.

19. Mohapatra SS and Boyapalle S: Epidemiologic, experimental, and clinical links between respiratory syncytial virus infection and asthma. Clin Microbiol Rev 21: 495-504, 2008.

20. Metzgar D, Osuna M, Kajon AE, Hawksworth AW, Irvine M and Russell KL: Abrupt emergence of diverse species B adenoviruses at US military recruit training centers. J Infect Dis 196: $1465-1473,2007$.

21. Centers for disease control and prevention. Centers for disease control and prevention, National Center for Immunization and Respiratory Diseases (NCIRD), Division of Viral Diseases (DVD) Web site. https://www.cdc.gov/ncird/overview/websites. html\#dvd. Accessed November 14, 2016

22. Centers for Disease Control and Prevention (CDC): Prevention and control of seasonal influenza with vaccines; Recommendations of the Advisory Committee on Immunization Practices--United States, 2013-2014. MMWR Recomm Rep 62: 1-4314, 2013.

23. Kuypers J, Martin ET, Heugel J, Wright N, Morrow R and Englund JA: Clinical disease in children associated with newly described coronavirus subtypes. Pediatrics 119: e70-e76, 2007.
24. Kahn JS: Epidemiology of human metapneumovirus. Clin Microbiol Rev 19: 546-557, 2006.

25. Zhang D, He Z, Xu L, Zhu X, Wu J, Wen W, Zheng Y, Deng Y, Chen J, Hu Y, et al: Epidemiology characteristics of respiratory viruses found in children and adults with respiratory tract infections in southern China. Int J Infect Dis 25: 159-164, 2014.

26. Bellau-Pujol S, Vabret A, Legrand L, Dina J, Gouarin S, Petitjean-Lecherbonnier J, Pozzetto B, Ginevra C and Freymuth F: Development of three multiplex RT-PCR assays for the detection of 12 respiratory RNA viruses. J Virol Methods 126: 53-63, 2005.

27. Bezerra PG, Britto MC, Correia JB, Duarte Mdo C, Fonceca AM, Rose K, Hopkins MJ, Cuevas LE and McNamara PS: Viral and atypical bacterial detection in acute respiratory infection in children under five years. PLoS One 6: e18928, 2011.

28. Auburn H, Zuckerman M, Broughton S, Greenough A and Smith M: Detection of nine respiratory RNA viruses using three multiplex RT-PCR assays incorporating a novel RNA internal control transcript. J Virol Methods 176: 9-13, 2011.

29. Schwartz J: Air pollution and children's health. Pediatrics 113 (4 Suppl): S1037-S1043, 2004.

30. Trasande L and Thurston GD: The role of air pollution in asthma and other pediatric morbidities. J Allergy Clin Immunol 115: 689-699, 2005

31. Bono R, Romanazzi V, Bellisario V, Tassinari R, Trucco G, Urbino A, Cassardo C, Siniscalco C, Marchetti P and Marcon A: Air pollution, aeroallergens and admissions to pediatric emergency room for respiratory reasons in Turin, northwestern Italy. BMC Public Health 16: 722, 2016.

32. Pizzi C, Arpino G, Acampora G, Aiello N, DE Rosa A, Diaferia I, DI Nunzio A, Fragna G, Franco A, Russo M, et al: Cancer prevalence in the city of Naples: Contribution of the GP database analyses to the cancer registries network. Mol Clin Oncol 1: 726-732, 2013.

33. Lipfert FW: Long-term associations of morbidity with air pollution: A Catalogue and Synthesis: Jul 5, 2017 (Epub ahead of print).

34. Ding PH, Wang GS, Guo YL, Chang SC and Wan GH: Urban air pollution and meteorological factors affect emergency department visits of elderly patients with chronic obstructive pulmonary disease in Taiwan. Environ Pollut 224: 751-758, 2017.

35. Yoshizaki K, Brito JM, Silva LF, Lino-Dos-Santos-Franco A, Frias DP, E Silva RC, Amato-Lourenço LF, Saldiva PH, de Fátima Lopes Calvo Tibério I, Mauad T and Macchione M: The effects of particulate matter on inflammation of respiratory system: Differences between male and female. Sci Total Environ 586: 284-295, 2017.

36. Lagorio S, Forastiere F, Pistelli R, Iavarone I, Michelozzi P, Fano V, Marconi A, Ziemacki G and Ostro BD: Air pollution and lung function among susceptible adult subjects: A panel study. Environ Health 5: 11, 2006.

37. Bono R, Tassinari R, Bellisario V, Gilli G, Pazzi M, Pirro V, Mengozzi G, Bugiani M and Piccioni P: Urban air and tobacco smoke as conditions that increase the risk of oxidative stress and respiratory response in youth. Environ Res 137: 141-146, 2015.

38. Dominici F, Peng RD, Bell ML, Pham L, McDermott A, Zeger SL and Samet JM: Fine particulate air pollution and hospital admission for cardiovascular and respiratory diseases. JAMA 295: 1127-1134, 2006

39. Dominici F, McDermott A, Daniels M, Zeger SL and Samet JM: Revised analyses of the national morbidity, mortality, and air pollution study: Mortality among residents of 90 cities. J Toxicol Environ Health A 68: 1071-1092, 2005.

40. Bono R, Bellisario V, Romanazzi V, Pirro V, Piccioni P, Pazzi M, Bugiani $M$ and Vincenti M: Oxidative stress in adolescent passive smokers living in urban and rural environments. Int J Hyg Environ Health 217: 287-293, 2014.

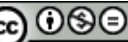

This work is licensed under a Creative Commons Attribution-NonCommercial-NoDerivatives 4.0 International (CC BY-NC-ND 4.0) License. 